\title{
Erratum to: Genetic and toxicologic investigation of Sudden Cardiac Death in a patient with Arrhythmogenic Right Ventricular Cardiomyopathy (ARVC) under cocaine and alcohol effects
}

Francesca Cittadini • Nadia De Giovanni • Mireia Alcalde • Sara Partemi • Arnaldo Carbone • Oscar Campuzano • Ramon Brugada $\cdot$ Antonio Oliva

Published online: 19 December 2014

(C) Springer-Verlag Berlin Heidelberg 2014

\section{Erratum to: Int J Legal Med}

DOI: 10.1007/s00414-014-1119-5

The original version of this article, unfortunately, contained an error.

Arnaldo Carbone was inadvertently omitted in the original version. He definitely contributed to the article. His name and affiliation now appears in this article.

The online version of the original article can be found at http://dx.doi.org/ 10.1007/s00414-014-1119-5.

F. Cittadini $\cdot$ N. De Giovanni $\cdot$ S. Partemi $(\bowtie) \cdot$ A. Oliva Institute of Public Health, Section of Legal Medicine, Catholic University, Rome, Italy

e-mail: sarapartemi@gmail.com

M. Alcalde $\cdot$ O. Campuzano $\cdot$ R. Brugada

Cardiovascular Genetics Centre, University of Girona-IDIBGI,

Girona, Spain

\section{A. Carbone}

Institute of Pathology, Catholic University, Rome, Italy 